\title{
Associations of self-reported physical activity and depression in 10,000 Irish adults across harmonised datasets: a DEDIPAC-study
}

Cillian P. Mc Dowell ${ }^{1 *}$, Angela Carlin ${ }^{1,2}$, Laura Capranica ${ }^{3}$, Christina Dillon4, Janas M. Harrington ${ }^{5}$, Jeroen Lakerveld ${ }^{6}$, Anne Loyen 7 , Fiona Chun Man Ling ${ }^{1,8,9}$, Johannes Brug ${ }^{6,10}$, Ciaran MacDonncha ${ }^{1,11}$ and Matthew P. Herring ${ }^{1,11}$

\begin{abstract}
Background: Depression is a prevalent, debilitating, and often recurrent mood disorder for which successful firstline treatments remains limited. The purpose of this study was to investigate the cross-sectional associations between self-reported physical activity (PA) and depressive symptoms and status among Irish adults, using two existing datasets, The Irish Longitudinal Study on Ageing (TILDA) and The Mitchelstown Cohort Study.

Methods: The two selected databases were pooled $(n=10,122)$, and relevant variables were harmonized. PA was measured using the short form International Physical Activity Questionnaire. Depressive symptoms were measured by the Center for Epidemiologic Studies Depression (CES-D) questionnaire. Participants were classified as meeting World Health Organization moderate-to-vigorous PA (MVPA) guidelines or not, and divided into tertiles based on weekly minutes of MVPA. A CES-D score of $\geq 16$ indicated elevated depressive symptoms. Data collection were conducted in 2010-2011.

Results: Significantly higher depressive symptoms were reported by females $(7.11 \pm 7.87)$ than males $(5.74 \pm 6.86 ; p$ $<0.001$ ). Following adjustment for age, sex, BMI, and dataset, meeting the PA guidelines was associated with $44.7 \%$ ( $95 \%$ Cl: 35.0 to $52.9 ; p<0.001$ ) lower odds of elevated depressive symptoms. Compared to the low PA tertile, the middle and high PA tertiles were associated with $25.2 \%$ (95\%Cl: 8.7 to 38.6; $p<0.01$ ) and 50.8\% (95\%Cl: 40.7 to 59.2; $p<0.001$ ) lower odds of elevated depressive symptoms, respectively.
\end{abstract}

Conclusion: Meeting the PA guidelines is associated with lower odds of elevated depressive symptoms, and increased volumes of MVPA are associated with lower odds of elevated depressive symptoms.

Keywords: Physical activity, Mental health, Elderly, Ireland, Cross-sectional

\section{Background}

Depression is a prevalent, debilitating, and often recurrent mood disorder $[1,2]$ that affects over 300 million people globally [1] and is the second leading cause of global disability [3]. The financial burden associated with depression continues to grow, due largely to increasing treatment costs and wider societal costs of lost productivity [4]. Depression is the mental disorder with the

\footnotetext{
*Correspondence: cillian.mcdowell@ul.ie

'Department of Physical Education and Sport Sciences, University of Limerick, Limerick, Ireland

Full list of author information is available at the end of the article
}

highest cost implications in Europe, accounting for over $€ 90$ billion in direct and indirect cost across Europe [4].

Successful treatment of depression with traditional first-line treatments, such as psychotherapy and pharmacotherapy, remains limited [5]. Exercise has been show to be a viable treatment for depression and depressive symptoms [6, 7]; however, evidence indicates that approximately $63 \%$ of people with mental health problems, including depression, do not seek specialist treatment and only half of those who do appear to improve [8]. Thus, there is a continued need to identify and

(c) The Author(s). 2018 Open Access This article is distributed under the terms of the Creative Commons Attribution 4.0 International License (http://creativecommons.org/licenses/by/4.0/), which permits unrestricted use, distribution, and reproduction in any medium, provided you give appropriate credit to the original author(s) and the source, provide a link to the Creative Commons license, and indicate if changes were made. The Creative Commons Public Domain Dedication waiver (http://creativecommons.org/publicdomain/zero/1.0/) applies to the data made available in this article, unless otherwise stated. 
investigate cost-effective prevention and treatment strategies that are effective and more accessible.

The salutary benefits of regular physical activity (PA) for mental health are well-established [9] and without the physiologic side effects and costs associated with antidepressants and psychotherapy [10]. In the context of depression, evidence supports: (i) significantly lower PA levels among adults with depression compared to adults without depression [11, 12]; (ii) inverse associations between PA and onset of depression [13, 14]; and (iii) that habitual PA may moderate treatment response [15]. However, many studies have not used validated instruments to capture important features of PA such as type, frequency, intensity, and duration, and the use of inconsistent self-report measures of PA between studies has limited the ability to examine dose-response relationships between PA and depression [13]. Despite this, large-scale studies exist that have measured PA and depression, though this research question often was not the primary focus of the original research [16]. Furthermore, in studies that did address PA as potential correlate of depression, different methodological approaches have been adopted, limiting the possibility to generalize the findings [13].

The cost of gathering such data is significant and research funders often emphasize maximising the potential of existing data resources through data sharing and secondary analysis [17-19]. The research and knowledge potential of existing datasets can be further exploited through dataset pooling and subsequent harmonisation of variables [17, 20-23]. Reported benefits of pooling include increased statistical power, potential for subgroup analysis and comparative research, increased exposure heterogeneity and generalisability, and increased cost-efficiency of research programmes $[17,24-26]$.

Thus, the aim of the current investigation was to harmonise and integrate two existing datasets in order to increase statistical power and generalisability in investigating and quantifying the association between meeting PA guidelines and elevated depressive symptoms, and to explore whether larger associations are observed with increased PA, in a large cross-sectional population sample of Irish adults. It is hypothesised that meeting PA guidelines will be associated with lower odds of elevated depressive symptoms, with lower odds of elevated depressive symptoms observed with greater volumes of PA.

\section{Methods}

This study used Strengthening the Reporting of Observational Studies in Epidemiology (STROBE) recommendations to guide reporting [27].

\section{Selection of participating studies}

The platform for the current research was the DEterminants of DIet and Physical ACtivity Knowledge Hub
(DEDIPAC-KH), a pan-European joint programme initiative active from 2013 to 2016 . The focus of DEDIPAC was to better understand how individual and contextual factors influence diet, PA, and sedentary behaviour [28, 29]. Within DEDIPAC, a compendium of relevant and accessible datasets regarding the listed health risk behaviours and their determinants was developed [30]. Datasets for inclusion in the compendium were identified by: i) a search of the CORDIS project platform, which is the European Commission's primary public repository and portal to disseminate information on all EU-funded research projects and their results, ii) an examination of existing recent literature reviews and noting the nature of datasets used, and iii) recommendation from the DEDIPAC network and expert consultation. The compendium provides information on the study, the study population, the determinants and health behaviours measured and level of accessibility. The compendium is accessible through https://www.dedipac.eu.

On examination of the compendium, 23 datasets were noted that measured both PA behaviour and a psychological determinant of some nature (e.g. motivation, perceived competence, anxiety, depression etc.). An evaluation of the available data dictionaries which were either publicly available or secured directly from the targeted dataset owners revealed five relevant datasets (three Irish, one Dutch, and one multi-nation) which had potential for harmonisation (i.e., PA and depression measured using a same or similar methodology). Target variables (including relevant covariates) were agreed and listed by three authors (CMcD, CMacD, MPH). The dataset owners were subsequently approached for access to the specific target variables. Of these, all agreed to participate; however, the multi-national study was inaccessible within the timeframe of the study. Therefore, the Dutch study was also excluded due to its smaller sample and nationality that differed from the remaining three studies. Another study (the Cork Children's Lifestyle Survey) was subsequently excluded as it assessed lifetime diagnosis of depression rather than current depressive symptoms. Appropriate data access agreements were signed as required. Only cross-sectional data for datasets were available. Thus, two datasets, The Irish Longitudinal Study on Ageing (TILDA) and The Mitchelstown Cohort Study together consisting of 10,122 Irish adults, were harmonised for the present study.

\section{Participating datasets}

The Irish Longitudinal Study on Ageing (TILDA) is a large $(n=8329)$ prospective cohort study that assesses the social, economic, and health circumstances of community dwelling adults aged $\geq 50$ years and their partners of any age in Ireland [31]. For the current study, the first wave of data collected in 2011 was used. PA was 
measured using the short International Physical Activity Questionnaire (IPAQ-SF) [32], in which respondents are asked to report the number of days and the duration of the vigorous, moderate, and walking activities they undertook during the last seven days. Depression was measured with the Center for Epidemiologic Studies Depression (CES-D) questionnaire [33].

The Mitchelstown Cohort Study provided data $(n=$ 1804) from the second phase of the Cork and Kerry Diabetes and Heart Disease Study [34], designed to assess diabetes and heart disease among 55-74 year-old adults. Data collection began in 2010. PA was measured with the IPAQ-SF while depression was measured using the CES-D.

\section{Harmonisation process}

A target list of relevant variables that may influence the association between PA and depression, based on a logical, theoretical, or prior empirical relation with PA and/or depression, and that had potential for data harmonisation (i.e., same or similar measure) was generated from the two included datasets. Appropriate variable harmonisation methods for PA, depression, and participant age, sex, and body mass index (BMI) were agreed by a six-person expert consensus group from within DEDIPAC (Table 1). These variables were then harmonised to form a large PA and mental health integrated dataset.

\section{Data analysis}

PA data were processed according to the IPAQ guidelines for data processing and analysis [35], and respondents were categorised as meeting or not meeting World Health Organization PA guidelines (i.e., $\geq 150$ min.week $^{-}$ 1 of MVPA, $\geq 75$ min.week ${ }^{-1}$ of vigorous PA, or $\geq 500$ MET.min.week ${ }^{-1}$ ) [36]. As the PA data were positively skewed, within individual datasets and across the integrated dataset participants were divided into tertiles based on weekly minutes of MVPA (i.e., 0 min.week ${ }^{-1}$, 10-295 min.week ${ }^{-1}$, and $\geq 300$ min.week ${ }^{-1}$ ). CES-D scores range from 0 to 60 , and individuals at risk for clinical depression were indicated by scores $\geq 16$ [33]; this cut-off score has demonstrated $100 \%$ sensitivity and $87.6 \%$ specificity among adults [37]. Respondents above this cut-off score are referred to as having elevated depressive symptoms throughout the current manuscript as they are at increased risk of depression; however, meeting the cut-off score does not necessarily indicate the presence of clinically diagnosed depression. BMI was categorized as underweight, normal weight, overweight, and obese using established thresholds of $<18.5 \mathrm{~kg} \cdot \mathrm{m}^{-2}$, $18.5-24.99 \mathrm{~kg} \cdot \mathrm{m}^{-2}, 25-29.99 \mathrm{~kg} \cdot \mathrm{m}^{-2}$, and $\geq 30 \mathrm{~kg} \cdot \mathrm{m}^{-2}$, respectively [38]. Statistical analyses were conducted using SPSS Version 22.0 (Armonk, NY: IBM Corp.).

\section{Within dataset analyses}

For descriptive purposes, Chi-square tests examined differences in proportions of elevated depressive symptom status, ten-year age categories, sex, BMI categories, and meeting PA guidelines between datasets. For significant Chi-square tests, $Z$ tests were calculated for column proportions for each row in the Chi-square contingency table and adjusted using a Bonferroni correction to provide further detail regarding PA and depression across the different levels of covariates [39]. Within each dataset, binomial logistic regression quantified crude and adjusted associations between PA and elevated depressive symptoms. Covariates in adjusted models were age, sex, and BMI.

\section{Integrated dataset analysis}

Chi-square tests examined differences in elevated depressive symptom status, age categories, sex, and BMI categories, between individuals meeting and not meeting

Table 1 Information on data harmonisation across datasets

\begin{tabular}{|c|c|c|c|}
\hline Concept measured & TILDA & Mitchelstown Cohort Study & Harmonisation method \\
\hline PA & $\begin{array}{l}\text { IPAQ - Self-reported weekly minutes } \\
\text { of moderate and vigorous PA }\end{array}$ & $\begin{array}{l}\text { IPAQ - Self-reported weekly } \\
\text { minutes of moderate and } \\
\text { vigorous PA }\end{array}$ & $\begin{array}{l}\text { Weekly minutes of moderate and vigorous PA } \\
\text { were summed. Participants were categorised as } \\
\text { meeting/not meeting PA guidelines and divided } \\
\text { into tertiles of weekly minutes of MVPA within } \\
\text { each study and across the integrated dataset }\end{array}$ \\
\hline Depression & CES-D (continuous score) & CES-D (continuous score) & $\begin{array}{l}\text { Participants with CES-D scores of } \geq 16 \text { were } \\
\text { classified as at-risk for depression }\end{array}$ \\
\hline Age & $\begin{array}{l}\text { Age reported for } 50-79 \text { years (ages }<50 \\
\text { reported as 49; ages }>79 \text { were reported } \\
\text { as } 80 \text { ) }\end{array}$ & Age (5 year categories) & Divided into 10 year categories \\
\hline Sex & Female and male & Female and male & Females and males grouped \\
\hline BMI & $\begin{array}{l}\text { BMI (categorical) calculated from nurse } \\
\text { measured height weight }\end{array}$ & $\begin{array}{l}\text { BMI (continuous) calculated } \\
\text { from measured height weight }\end{array}$ & $\begin{array}{l}\text { Split into underweight, normal weight, overweight, } \\
\text { and obese using standard cut-offs }\end{array}$ \\
\hline
\end{tabular}

$B M I$ Body mass index, CES-D Center for Epidemiological Studies Depression, IPAQ International physical activity questionnaire, PA Physical activity; TILDA The Irish longitudinal study on ageing 
PA guidelines. Binomial logistic regression quantified crude and adjusted associations between PA and elevated depressive symptom status. Covariates in adjusted models were age, sex, BMI, and dataset. Likelihood ratio tests examined covariate significance. One-way ANOVAs followed by Bonferroni-corrected post-hoc tests quantified differences in depressive symptoms between those meeting and not meeting PA guidelines, PA tertiles, and sexes. Hedges' $g$ effect sizes and associated 95\% confidence intervals $(95 \% \mathrm{CI})$ were calculated to quantify the magnitude of differences in depressive symptom scores between meeting PA guidelines, PA tertiles, and sexes [40]. Effect sizes of 0.2, 0.5, and 0.8 can been used as cut-offs for small, medium, and large effects, respectively [41].

\section{Results}

A total of 10,133 and 7809 respondents were included in crude and adjusted analyses, respectively. The overall prevalence of elevated depressive symptoms was $10.9 \%$. Females were more likely to report elevated depressive symptoms $\left(X^{2}(1, N=10,133)=54.49, p<0.001\right)$ than males $(12.9 \%$ vs $8.3 \%)$, and reported significantly higher depressive symptoms $(7.11 \pm 7.87)$ than men $(5.74 \pm 6.86$; $\mathrm{F}_{(1,10,131)}=84.59, p<0.001 ; g=0.18 ; 95 \%$ CI: 0.15 to 0.22$)$.

\section{Participant characteristics within datasets}

Harmonised data characteristics are presented in Table 2. Elevated depressive symptom status $\left(\chi^{2}(1, N=10,133)\right.$ 65.79, $p<0.001)$, meeting PA guidelines $\left(\chi^{2}(1, \mathrm{~N}=\right.$ $10,133)=156.61, p<0.001)$, sex $\left(x^{2}(2, N=10,133)=\right.$ 11.57, $p<0.001)$, and age $\left(x^{2}(4, \mathrm{~N}=10,122)=664.55, p\right.$ $<0.001$ were significantly different between studies. Results from follow-up $Z$ tests are shown in Table 2 . Briefly, a significantly greater proportion of Mitchelstown participants reported elevated depressive symptoms, did not meet PA guidelines, and were aged 5059 years and male (all $p<0.05)$.

\section{Within dataset analyses}

Table 3 presents crude and adjusted odds ratios for the associations between meeting PA guidelines and PA tertiles, and elevated depressive symptoms within each dataset. Significant crude associations remained robust following adjustment for age, sex, and BMI. Meeting PA guidelines was associated with $49.8 \%$ (95\% CI: 39.2 to 58.5; $p<0.001$ ) and $27.8 \%$ (95\% CI: 2.8 to $46.4 ; p<0.05$ ) lower odds of elevated depressive symptoms in TILDA and Mitchelstown, respectively.

Similar to crude associations, following adjustment for age, sex, and BMI, the middle PA tertile was associated with $26.4 \%$ (95\% CI: 7.4 to $41.5 ; p \leq 0.001)$ and $30.2 \%$ (95\% CI: -0.5 to $51.5 ; p>0.05)$ lower odds of elevated depressive symptoms in TILDA and Mitchelstown, respectively; the
Table 2 Study characteristics

\begin{tabular}{|c|c|c|}
\hline & TILDA & Mitchelstown \\
\hline MVPA (minutes (median IQR)) & $90.00(600.00)$ & $0.00(180.00)$ \\
\hline \multicolumn{3}{|l|}{ PA (n (\%)) } \\
\hline Not Meeting PA guidelines & $4471(53.8)$ & $1259(69.0)$ \\
\hline Meeting PA guidelines & $3858(46.3)$ & $545(30.2)$ \\
\hline \multicolumn{3}{|l|}{ Depression status (n (\%)) } \\
\hline Not Depressed & $7522(90.3)$ & $1511(83.8)$ \\
\hline Depressed & $807(9.7)$ & $293(16.2)$ \\
\hline \multicolumn{3}{|l|}{ Age (n (\%)) } \\
\hline$<50$ & $327(3.9)_{a}$ & $2(0.1)_{b}$ \\
\hline $50-59$ & $3210(38.6)_{a}$ & $973(53.9)_{\mathrm{b}}$ \\
\hline $60-69$ & $2540(30.5)_{a}$ & $801(44.4)_{b}$ \\
\hline $70-79$ & $1636(19.7)_{a}$ & $28(1.6)_{b}$ \\
\hline $80+$ & $605(7.3)_{a}$ & $0(0.0)_{b}$ \\
\hline \multicolumn{3}{|l|}{$\operatorname{Sex}(n(\%))$} \\
\hline Male & $3706(44.5)_{a}$ & $882(48.9)_{b}$ \\
\hline Female & $4623(55.5)_{a}$ & $922(51.1)_{b}$ \\
\hline \multicolumn{3}{|l|}{ BMI (n (\%)) } \\
\hline Underweight & $32(0.5)$ & $7(0.4)$ \\
\hline Normal & $1353(22.5)$ & $401(22.1)$ \\
\hline Overweight & $2576(42.8)$ & $821(45.3)$ \\
\hline Obese & 2056 (34.2) & 584 (32.2) \\
\hline
\end{tabular}

Different subscript letters indicate a subset of each category whose column proportions differ statistically significantly at the .05 level

$B M I$ Body mass index, MVPA Moderate-to-vigorous physical activity, TILDA The Irish longitudinal study on ageing

high PA tertile was associated with 54.6\% (95\% CI: 43.3 to 63.6; $p<0.001$ ) and $38.5 \%$ (95\% CI: 11.2 to $57.4 ; p<0.01$ ) lower odds of elevated depressive symptoms in TILDA and Mitchelstown, respectively.

\section{Participant characteristics across integrated dataset}

Participant characteristics by PA guideline adherence in the integrated dataset are presented in Table 4. Elevated depressive symptom status $\left(\chi^{2}(1, N=10,133)=94.60\right.$, $p<0.001)$, sex $\left(x^{2}(1, \mathrm{~N}=10,133)=243.30, p<0.001\right)$, age $\left(\mathrm{X}^{2}(4, \mathrm{~N}=10,122)=168.63, p<0.001\right)$, and BMI $\left(\mathrm{X}^{2} \quad(3, N=7818)=22.03, p<0.001\right)$ significantly differed between meeting and not meeting PA guidelines. Briefly, people not meeting PA guidelines were significantly more likely to report elevated depressive symptoms and be female, aged $70-79$ or $\geq 80$ years, and obese (all $p<0.05$ ).

\section{Integrated dataset analyses}

Table 3 presents crude and adjusted odds ratios for the associations between meeting PA guidelines and PA tertiles, and elevated depressive symptoms across the integrated dataset. Odds ratios for covariates in adjusted 
Table 3 Odds ratios (OR) and 95\% confidence intervals (CI) derived from binominal logistic regression analyses as indicators of associations between physical activity (PA) and depressive symptoms

\begin{tabular}{|c|c|c|c|}
\hline & TILDA OR (95\%Cl) & Mitchelstown OR (95\%Cl) & Integrated Dataset OR (95\%Cl) \\
\hline \multicolumn{4}{|l|}{ Crude } \\
\hline \multicolumn{4}{|l|}{ PA Guidelines } \\
\hline Not Meeting PA guidelines & REF & REF & REF \\
\hline Meeting PA guidelines & 0.509 (0.436 to 0.594$)$ & 0.685 (0.512 to 0.915$)$ & 0.514 (0.449 to 0.589$)$ \\
\hline \multicolumn{4}{|l|}{ Adjusted } \\
\hline \multicolumn{4}{|l|}{ PA Guidelines } \\
\hline Not Meeting PA guidelines & REF & REF & REF \\
\hline Meeting PA guidelines & 0.502 (0.415 to 0.608$)$ & 0.722 (0.536 to 0.972 ) & 0.557 (0.474 to 0.655$)$ \\
\hline \multicolumn{4}{|l|}{ Crude } \\
\hline \multicolumn{4}{|l|}{ PA Tertiles } \\
\hline Low PA Tertile & REF & REF & REF \\
\hline Middle PA Tertile & 0.681 (0.560 to 0.829 ) & 0.704 (0.492 to 1.008$)$ & 0.663 (0.558 to 0.787 ) \\
\hline High PA Tertile & 0.469 (0.393 to 0.559$)$ & 0.561 (0.393 to 0.803 ) & 0.455 (0.389 to 0.532 ) \\
\hline \multicolumn{4}{|l|}{ Adjusted } \\
\hline \multicolumn{4}{|l|}{ PA Tertiles } \\
\hline Low PA Tertile & REF & REF & REF \\
\hline Middle PA Tertile & 0.736 (0.585 to 0.926$)$ & 0.698 (0.485 to 1.005$)$ & 0.736 (0.606 to 0.893$)$ \\
\hline High PA Tertile & 0.454 (0.364 to 0.567$)$ & 0.615 (0.426 to 0.888$)$ & 0.489 (0.404 to 0.591$)$ \\
\hline
\end{tabular}

Table 4 Participant characteristics

\begin{tabular}{|c|c|c|}
\hline & $\begin{array}{l}\text { Meeting PA Guidelines } \\
(\mathrm{n}(\%))\end{array}$ & $\begin{array}{l}\text { Not Meeting PA } \\
\text { Guidelines (n (\%)) }\end{array}$ \\
\hline \multicolumn{3}{|l|}{ Depression status } \\
\hline Depressed & $327(7.4)$ & 773 (13.5) \\
\hline Not depressed & 4076 (92.6) & 4957 (86.5) \\
\hline \multicolumn{3}{|l|}{ Age (years) } \\
\hline$<50$ & $175(4.0)_{a}$ & $154(2.7)_{b}$ \\
\hline $50-59$ & $1987(45.2)_{a}$ & $2196(38.4)_{b}$ \\
\hline $60-69$ & $1482(33.7)_{a}$ & $1859(32.5)_{a}$ \\
\hline 70-79 & $609(13.9)_{a}$ & $1055(18.4)_{b}$ \\
\hline $80+$ & $144(3.3)_{a}$ & $461(8.1)_{\mathrm{b}}$ \\
\hline \multicolumn{3}{|l|}{ Sex } \\
\hline Male & $2381(54.1)$ & 2207 (38.5) \\
\hline Female & $2022(45.9)$ & $3523(61.5)$ \\
\hline \multicolumn{3}{|l|}{ BMI } \\
\hline Underweight & $15(0.4)_{a}$ & $24(0.6)_{a}$ \\
\hline Normal & $787(22.7)_{a}$ & $966(22.2)_{a}$ \\
\hline Overweight & $1589(45.8)_{a}$ & $1802(41.4)_{b}$ \\
\hline Obese & $1078(31.1)_{a}$ & $1557(35.8)_{b}$ \\
\hline
\end{tabular}

Different subscript letters indicate a subset of each category whose column proportions differ statistically significantly at the .05 level $B M I$ Body mass index, PA Participant characteristics analyses are reported in Additional file 1: Table S1. Significant crude associations remained robust following adjustment for age, sex, BMI, and dataset. Compared to not meeting PA guidelines, meeting the guidelines was associated with $44.3 \%$ (95\% CI: 34.5 to $52.6 ; p<0.001$ ) lower odds of elevated depressive symptoms. Age, sex, and BMI were significant covariates (all $p<0.005$ ).

Significant crude associations remained robust following adjustment for age, sex, BMI, and dataset. The middle and high PA tertiles were associated with $26.4 \%$ (95\% CI: 10.7 to 39.4; $p<0.01$ ) and $51.1 \%$ (95\% CI: 40.9 to $59.6 ; p<0.001$ ) lower odds of elevated depressive symptoms, respectively. Age, sex, and BMI were significant covariates (all $p<0.05$ ).

Depressive symptoms were significantly higher among people not meeting MVPA guidelines $(7.43 \pm 7.95)$ than those meeting PA guidelines $\left(5.30 \pm 6.59 ; \mathrm{F}_{(1,10,131)}=\right.$ 200.71, $p<0.001 ; g=0.28$; 95\%CI: 0.25 to 0.32 ). Depressive symptoms significantly differed by PA tertile $(p<0.001)$. Post-hoc tests showed significantly lower depressive symptoms for the high PA tertile $(5.05 \pm 6.53)$ compared to the low $(7.60 \pm 8.03, p<0.001 ; g=0.3495 \% \mathrm{CI}$ : 0.30 to 0.39 ) and middle $(6.16 \pm 6.99, p<0.001 ; g=0.17$; $95 \%$ CI: 0.11 to $0.22)$ PA tertiles. The middle PA tertile also reported significantly lower depressive symptoms than the low PA tertile $(p<0.001 ; g=0.19 ; 95 \%$ CI: 0.13 to 0.24$)$.

\section{Discussion}

Using secondary analyses of pooled data from large-scale Irish studies, this work contributes to deepen the 
knowledge on the association between meeting PA guidelines and elevated depressive symptoms, and a potential dose-response in the PA-depression relationship, in a European country. A previous umbrella systematic review of psychological determinants of PA across the life course highlighted that the negative association between PA and depression/depressive symptoms' presents limited and no conclusive evidence [42]. The present study supports associations between meeting PA guidelines and lower odds of depression, and a dose response in the PA-depression relationship.

Approximately $10.9 \%$ of the current sample reported elevated depressive symptoms, supporting previous findings in worldwide [2] and Irish [43] samples. Females were significantly more likely to report higher depressive symptoms $(g=0.18)$, which is consistent with previous evidence [44]. Adjusted analyses, both within and across datasets, support the association between not meeting MVPA guidelines and elevated depressive symptoms, consistent with previous findings regarding the beneficial effects of meeting MVPA guidelines on depressive symptoms [13]. The $44 \%$ lower odds of reporting elevated depressive symptoms among people meeting MVPA guidelines is consistent with previous findings $[9,45]$.

A potential dose-response relationship was observed in the present study. Compared to the low PA tertile, the middle and high PA tertiles were associated with 26 and $51 \%$ lower odds of elevated depressive symptoms, respectively, such that participation in the highest volume of MVPA appeared to confer more benefits than a more moderate volume. Previous findings are limited and contradictory, and a clear dose-response relationship between PA and depression has not been readily apparent [13, 15]. Research by Dunn et al. (2005) [46] observed similar findings to ours in that significantly lower post-intervention depression scores among adults with mild to moderate major depressive disorder whose total energy expenditure was $17.5 \mathrm{kcal} / \mathrm{kg} /$ week for 12-weeks compared to those whose total energy expenditure was $7.0 \mathrm{kcal} / \mathrm{kg} /$ week [46]. Further, those who routinely engage in higher levels of PA have been shown to respond better to depression treatment than those who are less active [15]. Collectively, these findings support the need to engage in at least a moderate level of PA, with the potential for increased benefits with increased PA.

Although not examined in the present study, there is also evidence to suggest that compared to engaging in no PA, engaging in volumes of MVPA less than recommended levels [13], and increasing levels of light intensity PA [47], may also protect against depression. This may have important public health implications as, although the current study strongly supports the benefits of meeting PA guidelines, the wider research appears to indicate that any amount of PA is better than none.
The iterative steps for effective retrospective data harmonisation published by Fortier and colleagues (2017) [24] underpinned the harmonisation process within this study (e.g. definition of question, detailed characteristics regarding potential datasets, expert input, valid data input, etc.). In concordance with an effective data harmonisation process, the dataset owners were involved from an early stage and access to detailed information on the data collection procedures adopted by the two studies included was available. The implementation of such methodological rigour optimised the quality of the harmonisation process and, thereby the quality and scientific utility of the final database generated.

\section{Strengths and limitations}

The present study benefits from a large sample size, a PA measure that measured important components of $\mathrm{PA}$, such as frequency, duration, and intensity of PA, direct examination of meeting PA guidelines, and following rigorous harmonisation procedures. However, several limitations exist. There is the possibility of differences in sampling methodology across studies, while some differences between studies can be impossible to reconcile. For example, including other lifestyle and health behaviours, socio-economic status, and social support as covariates may influence the association between PA level and depression, yet differences in how they were measured made it impossible to include it as a covariate in the present analyses. Because of this, the field will benefit from a more standardised set of measurements across studies. Over-reporting of PA is frequently encountered in epidemiological research partly due to influences such as social desirability and recall bias [48] and may have led to respondents being misclassified as meeting PA guidelines in the present study; however, there is no evidence to suggest that reporting error should differ according to mental health status. Finally, due to the cross-sectional design of this study, causation cannot be deduced. Nonetheless, the current findings are to the authors' knowledge the first to provide support for the benefits of PA for depression, with indications of a dose-response relation, among a large, Irish sample.

\section{Conclusions}

Inverse associations between meeting PA guidelines and odds of reporting elevated depressive symptoms were observed, with stronger associations observed with increased volumes of MVPA. Future prospective cohort studies should examine this potential dose-response relationship and focus on potential moderators and mediators of the association between PA and depression in large, European-based samples. Further, more large-scale prospective studies in large European-based samples using objective measure of PA are required to establish 
cause and effect and to further elucidate the role of potential moderators and mediators of the PA-depression relationship.

\section{Additional file}

Additional file 1: Table S1. Odds ratios (OR) and 95\% confidence intervals (Cl) derived from binominal logistic regression analyses as indicators of association between physical activity (PA) and covariates and depressive symptoms. (DOCX $17 \mathrm{~kb}$ )

\section{Abbreviations \\ ANOVA: Analysis of Variance; BMI: Body Mass Index; CES-D: Center for Epidemiologic Studies Depression; DEDIPAC-KH: DEterminants of Dlet and Physical ACtivity Knowledge Hub; IPAQ-SF: International Physical Activity Questionnaire - Short Form; kg: kilogram; m: meter; min: minutes; MVPA: Moderate-to-Vigorous Physical Activity; PA: Physical Activity; TILDA: The Irish Longitudinal Study on Ageing}

\section{Acknowledgements}

We would like to sincerely thank The Irish Longitudinal Study on Ageing (TILDA), Trinity College, Dublin for providing access to their data and Dr. Janas Harrington, University College Cork for providing targeted data relating to the Mitchelstown Cohort Study.

\section{Funding}

The preparation of this paper was supported by the DEterminants of Dlet and Physical ACtivity (DEDIPAC) knowledge hub. This work is supported by the Joint Programming Initiative 'Healthy Diet for a Healthy Life'. The funding agencies supporting this work are: Ireland: The Health Research Board (HRB); Italy: Ministry of Education, University and Research (DEDIPAC F.S. 02.15 .02 COD. B84G14000040008; CDR2.PRIN 2010/11 COD. 2010KL2Y73_003)/ Ministry of Agriculture Food and Forestry Policies; The Netherlands: The Netherlands Organisation for Health Research and Development (ZonMw). The sponsors played no role in study design, methods, subject recruitment, data collection, analysis or preparation of the paper.

\section{Availability of data and materials}

The TILDA data that support the findings of this study are publicly available in the Irish Social Science Data Archive [http://www.ucd.ie/issda/data/tilda/] The Mitchelstown data that support the findings of this study are available from Dr. Janas Harrington, University College Cork, Cork, Ireland but restrictions apply to the availability of these data, which were used under license for the current study, and so are not publicly available. Additional characteristics and degree of accessibility to the original datasets pooled and harmonized in the current study are defined within the DEDIPAC Compendium of datasets (https://www.dedipac.eu/compendium)

\section{Authors' contributions}

$C M C D, C M a c D$, and $M H$ had full access to all data in the study and take responsibility for the integrity of the data and the accuracy of the data analysis. Study concept and design: CMCD, CMacD, and MH. Acquisition, analysis or interpretation of data: $C M C D, C M a c D, M H, J L, J B, C D$, and $J H$. Drafting of the manuscript: $C M C D, C M a c D, M H, A C, L C, C D, A L$, and FCML. Critical revision of the manuscript for important intellectual content: All authors. Intellectual content: All authors. Statistical analysis: CMCD and MH. All authors read and approved the final manuscript.

\section{Ethics approval and consent to participate}

The data collection procedures used in these original studies were in accordance with the ethical standards of the respective institutional research committees, the 1964 Helsinki Declaration, and its later amendments. Informed consent was obtained from all participants included in the original studies and all data was strictly confidential and anonymous. In the context of this ethical approval, access and permission to utilise the data from the original studies was received from the dataset owners at Trinity College Dublin and University College Cork, Ireland.

\section{Consent for publication}

\section{Competing interests}

The authors declare that they have no competing interests.

\section{Publisher's Note}

Springer Nature remains neutral with regard to jurisdictional claims in published maps and institutional affiliations.

\section{Author details}

${ }^{1}$ Department of Physical Education and Sport Sciences, University of Limerick, Limerick, Ireland. ${ }^{2}$ Centre for Exercise Medicine, Physical Activity and Health, School of Sport, Ulster University, Belfast, Northern Ireland.

${ }^{3}$ Department of Movement, Human and Health Sciences, University of Rome Foro Italico, Rome, Italy. ${ }^{4}$ National Suicide Research Foundation, University College Cork, Cork, Ireland. ${ }^{5}$ School of Public Health, University College Cork, Cork, Ireland. ${ }^{6}$ Department of Epidemiology and Biostatistics, Amsterdam Public Health research institute, VU University Medical Center, Amsterdam, The Netherlands. ${ }^{7}$ Department of Social and Occupational Health, Amsterdam Public Health research institute, VU University Medical Center, Amsterdam, the Netherlands. ${ }^{8}$ Institute of Sport, Exercise and Active Living, Victoria University, Melbourne, Australia. ${ }^{9}$ Department of Psychology, Faculty of Science \& Technology, Bournemouth University, Bournemouth, UK.

${ }^{10}$ Amsterdam School for Communication Research, University of Amsterdam, Amsterdam, the Netherlands. ${ }^{11}$ Health Research Institute, University of Limerick, Limerick, Ireland.

Received: 22 November 2017 Accepted: 12 June 2018

Published online: 01 July 2018

\section{References}

1. World Health Organization, 2017. Depression: A Global Public Health Concern. World Health Organization, Geneva. Available at: http://www.who. int/mediacentre/factsheets/fs369/en/. Accessed on Feb. 222018.

2. Kessler RC, Petukhova M, Sampson NA, Zaslavsky AM, Wittchen HU. Twelvemonth and lifetime prevalence and lifetime morbid risk of anxiety and mood disorders in the United States. Int J Methods Psychiatr Res. 2012;21: $169-84$.

3. Ferrari AJ, Charlson FJ, Norman RE, Patten SB, Freedman G, Murray CJ, et al. Burden of depressive disorders by country, sex, age, and year: findings from the global burden of disease study 2010. PLoS Med. 2013;10(11)

4. Olesen J, Gustavsson A, Svensson M, Wittchen HU, Jönsson B. The economic cost of brain disorders in Europe. Eur J Neurol. 2012:19(1):155-62.

5. Trivedi MH, Rush AJ, Wisniewski SR, Nierenberg AA, Warden D, Ritz L, et al. Evaluation of outcomes with citalopram for depression using measurementbased care in STAR* D: implications for clinical practice. Am J Psychiatry. 2006;163:28-40.

6. Gordon BR, McDowell CP, Hallgren M, Meyer JD, Lyons M, Herring MP. Association of Efficacy of resistance exercise training with depressive symptoms: meta-analysis and meta-regression analysis of randomized clinical trials. JAMA Psychiatry. 2018; https://doi.org/10.1001/jamapsychiatry. 2018.0572.

7. Schuch FB, Vancampfort D, Richards J, Rosenbaum S, Ward PB, Stubbs B. Exercise as a treatment for depression: a meta-analysis adjusting for publication bias. Psychiatry Res. 2016;77:42-51

8. Forsell $Y$. The pathway to meeting need for mental health services in Sweden. Psych Serv. 2006;57(1):114-9.

9. Physical Activity Guidelines Advisory Committee. Physical activity guidelines advisory committee report, 2008. Washington, DC: US: Department of Health and Human Services 2008; 2008. p. A1-H14.

10. Schuch FB, Vancampfort D, Rosenbaum S, Richards J, Ward PB, Stubbs B. Exercise improves physical and psychological quality of life in people with depression: a meta-analysis including the evaluation of control group response. Psychiatry Res. 2016;241:47-54.

11. Burton C, McKinstry B, Tătar AS, Serrano-Blanco A, Pagliari C, Wolters M. Activity monitoring in patients with depression: a systematic review. J Affect Disord. 2013;145(1):21-8

12. Helgadóttir B, Forsell Y, Ekblom Ö. Physical activity patterns of people affected by depressive and anxiety disorders as measured by accelerometers: a cross-sectional study. PLoS One. 2015;10(1) 
13. Mammen G, Faulkner G. Physical activity and the prevention of depression: a systematic review of prospective studies. Am J Prev Med. 2013;45(5):649-57.

14. Schuch FB, Vancampfort D, Firth J, Rosenbaum S, Ward PB, Silva ES, Hallgren $M$, et al. Physical activity and incident depression: a meta-analysis of prospective cohort studies. Am J Psychiatry. 2018; https://doi.org/10.1176/ appi.ajp.2018.171111194.

15. Hallgren M, Nakitanda OA, Ekblom Ö, Herring MP, Owen N, Dunstan D, et al. Habitual physical activity levels predict treatment outcomes in depressed adults: a prospective cohort study. Prev Med. 2016;88:53-8.

16. Artaud F, Dugravot A, Sabia S, Singh-Manoux A, Tzourio C, Elbaz A. Unhealthy behaviours and disability in older adults: Three-City Dijon cohort study. BMJ. 2013;347

17. Doiron D, Burton P, Marcon Y, Gaye A, Wolffenbuttel BH, Perola M, et al. Data harmonization and federated analysis of population-based studies: the BioSHaRE project. Emerg Themes Epidemiol. 2013;10(1):1.

18. Pisani E, AbouZahr C. Sharing health data: good intentions are not enough. Bull World Health Organ. 2010;88(6):462-6.

19. Wilkinson MD, Dumontier M, Aalbersberg IJ, Appleton G, Axton M, Baak A, et al. The FAIR guiding principles for scientific data management and stewardship. Sci Data. 2016;3:160018. https://doi.org/10.1038/sdata.2016.18.

20. Buffart LM, Kalter J, Chinapaw MJ, Heymans MW, Aaronson NK, Courneya KS, et al. Predicting OptimaL cAncer Rehabllitation and supportive care (POLARIS): rationale and design for meta-analyses of individual patient data of randomized controlled trials that evaluate the effect of physical activity and psychosocial interventions on health-related quality of life in cancer survivors. Syst Rev. 2013;2(1):1.

21. Schaap LA, Peeters GM, Dennison EM, Zambon S, Nikolaus T, SanchezMartinez M, et al. European project on OSteoArthritis (EPOSA): methodological challenges in harmonization of existing data from five European population-based cohorts on aging. BMC Musculoskelet Disord. $2011 ; 12(1): 1$

22. Fortier I, Doiron D, Little J, Ferretti V, L'Heureux F, Stolk RP, et al. Is rigorous retrospective harmonization possible? Application of the DataSHaPER approach across 53 large studies. Int J Epidemiol. 2011;40(5):1314-28.

23. Horwood LJ, Fergusson DM, Coffey C, Patton GC, Tait R, Smart D, et al. Cannabis and depression: an integrative data analysis of four Australasian cohorts. Drug Alcohol Depend. 2012;126(3):369-78.

24. Fortier I, Raina P, Van den Heuvel ER, Griffith LE, Craig C, Saliba M, et al. Maelstrom research guidelines for rigorous retrospective data harmonization. Int J Epidemiol. 2017:46(1):103-5.

25. Gallacher JE. The case for large scale fungible cohorts. Eur J Pub Health. 2007;17(6):548-9

26. Hutchinson DM, Silins E, Mattick RP, Patton GC, Fergusson DM, Hayatbakhsh $R$, et al. How can data harmonisation benefit mental health research? An example of the Cannabis cohorts research consortium. Aust N Z J Psychiatry. 2015;

27. Von Elm E, Altman DG, Egger M, Pocock SJ, Gøtzsche PC, Vandenbroucke $J P$. The strengthening the reporting of observational studies in epidemiology [STROBE] statement: guidelines for reporting observational studies. Gac Sanit. 2008;22(2):144-50.

28. Lakerveld J, Van Der Ploeg HP, Kroeze W, Ahrens W, Allais O, Andersen LF, et al. Towards the integration and development of a cross-European research network and infrastructure: the DEterminants of Dlet and physical ACtivity (DEDIPAC) knowledge hub. Int J Behav Nutr Phys Act. 2014;11(1):1

29. Brug J, van der Ploeg HP, Loyen A, Ahrens W, Allais O, Andersen LF, et al. Determinants of diet and physical activity (DEDIPAC): a summary of findings. Int J Behav Nutr Phys Act. 2017;14(1):150.

30. Lakerveld J, Loyen A, Ling F, De Craemer M, van der Ploeg HP, O'Gorman DJ, Carlin A, Capranica L, Kalter J, Oppert J-M, Chastin S, Cardon G, Brug J, MacDonncha C.. Identifying and sharing data for secondary data analysis of physical activity, sedentary behaviour and their determinants across the life course in Europe: general principles and an example from DEDIPAC. BMJ Open (In Press).

31. Kearney PM, Cronin H, O'Regan C, Kamiya Y, Savva GM, Whelan B, et al. Cohort profile: the Irish longitudinal study on ageing. Int J Epidemiol. 2011; 40(4):877-84.

32. Craig CL, Marshall AL, Sjöström M, Bauman AE, Booth ML, Ainsworth BE, et al. International physical activity questionnaire: 12-country reliability and validity. Med Sci Sports Exerc. 2003;35(8):1381-95.

33. Radloff LS. The CES-D scale. a self-report depression scale for research in the general population Appl Psychol Meas. 1977;1(3):385-401.
34. Kearney PM, Harrington JM, Mc Carthy VJ, Fitzgerald AP, Perry IJ. Cohort profile: the Cork and Kerry diabetes and heart disease study. Int J Epidemiol. 2013;42(5):1253-62.

35. International Physical Activity Questionnaire. Guidelines for Data Processing and Analysis of the International Physical Activity Questionnaire-Short and Long Forms; 2004. Available from: http://www.sdp.univ.fvg.it/sites/default/ files/IPAQ_English_self-admin_short.pdf.

36. World Health Organization. Global recommendations on physical activity for health. 2010. Available at: www.who.int/dietphysicalactivity/factsheet_ recommendations/en/. Accessed on 10/10/2017.

37. Beekman AT, Deeg DJH, Van Limbeek J, Braam AW, De Vries MZ, Van Tilburg W. Brief communication: criterion validity of the Center for Epidemiologic Studies Depression scale (CES-D): results from a community-based sample of older subjects in the Netherlands. Psychol Med. 1997;27(1):231-5.

38. World Health Organization. Obesity: preventing and managing the global epidemic. Geneva: WHO Tech Rep Ser 894; 2000. p. 252. Available at: http:// www.who.int/nutrition/publications/obesity/WHO_TRS_894/en/. Accessed on 10/10/2017.

39. Sharpe D. Your chi-square test is statistically significant: now what? Pract Assess Res Eval. 2015:20(8):2-10.

40. Cumming G. The new statistics why and how. Psychol Sci. 2013;

41. Cohen J. A power primer. Psychol Bull. 1992;112(1):155.

42. Cortis C, Puggina A, Pesce C, Aleksovska K, Buck C, Burns C, et al. Psychological determinants of physical activity across the life course: a" DEterminants of Dlet and physical ACtivity"(DEDIPAC) umbrella systematic literature review. PLoS One. 2017:12(8)

43. McDowell CP, Gordon BR, Herring MP. Sex-related differences in the association between grip strength and depression: results from the Irish longitudinal study on ageing. Exp Gerontol. 2018; https://doi.org/10.1016/j. exger.2018.02.010

44. McDowell CP, Campbell MJ, Herring MP. Sex-related differences in mood responses to acute aerobic exercise. Med Sci Sports Exerc. 2016;48(9):1798802.

45. Stubbs B, Koyanagi A, Schuch F, Firth J, Rosenbaum S, Veronese N, et al. Physical activity and depression: a large cross-sectional, population-based study across 36 low-and middle-income countries. Acta Psychiat Scand. 2016:134(6):546-56.

46. Dunn AL, Trivedi MH, Kampert JB, Clark CG, Chambliss HO. Exercise treatment for depression. efficacy and dose response Am J Prev Med. 2005 . 28(1):1-8.

47. Loprinzi PD. Objectively measured light and moderate-to-vigorous physical activity is associated with lower depression levels among older US adults. Aging Ment Health. 2013;17(7):801-5.

48. Winckers AN, Mackenbach JD, Compernolle S, Nicolaou M, van der Ploeg $H P$, De Bourdeaudhuij I, et al. Educational differences in the validity of selfreported physical activity. BMC Public Health. 2015;15(1):1299.

\section{Ready to submit your research? Choose BMC and benefit from:}

- fast, convenient online submission

- thorough peer review by experienced researchers in your field

- rapid publication on acceptance

- support for research data, including large and complex data types

- gold Open Access which fosters wider collaboration and increased citations

- maximum visibility for your research: over $100 \mathrm{M}$ website views per year

At BMC, research is always in progress.

Learn more biomedcentral.com/submissions 